\title{
Cost comparison of illness in patients with rheumatoid arthritis, osteoarthritis and fibromyalgia syndrome
}

\author{
Maryam Mobini $^{1 *}$, Reza Ali Mohammadpour ${ }^{2}$, Bahram Tahmasbi $^{3}$ and Tahereh Karimi ${ }^{4}$ \\ ${ }^{1}$ Associate Professor, Department of Internal Medicine, Diabetes Research Centre, Faculty of Medicine, Mazandaran University of \\ Medical Sciences, Sari, Iran. ${ }^{2}$ Associate Professor, Department of Biostatistics, Diabetes Research Centre, Faculty of Health, \\ Mazandaran University of Medical Sciences, Sari, Iran. ${ }^{3}$ Assistant Professor, Department of Healthcare Management, Amol Faculty \\ of Nursing and Midwifery, Mazandaran University of Medical Sciences, Sari, Iran. ${ }^{4}$ Medical Student, Faculty of Medicine, \\ Mazandaran University of Medical Sciences, Sari, Iran
}

\begin{abstract}
Musculoskeletal disorders are prevalent and expensive diseases. This study was conducted to estimate and compare the costs of illness of three musculoskeletal conditions. Patients with rheumatoid arthritis (RA), knee osteoarthritis (OA), and fibromyalgia syndrome (FMS) who referred to a rheumatologist completed questionnaires about their socio-demographic condition, clinical status, and the costs of their disease (direct costs included visits, laboratory tests, imaging, and medications; indirect costs included absence from paid work, functional inability, and paid and nonpaid household help) in the preceding year. Statistical analyses were performed by descriptive analysis, and one way ANOVA and chi-square test were used for the comparison of three groups using SPSS ver 20. A p-value $<0.05$ was considered significant. Three groups of participants were included in this study: RA, OA, and FMS ( $\mathrm{n}=90$ per group). The mean annual disease-related total costs per patient were $\$ 336.23 \pm 215.7$ for RA, $\$ 360.02 \pm 164.3$ for knee OA, and $\$ 240.67 \pm 141.2$ for FMS; differences between these numbers were statistically significant $(\mathrm{P}<0.001)$. Total costs were higher for $\mathrm{OA}$, mainly because of the utilization of complementary medicine, while indirect costs were higher for patients with RA. Total costs were found to be higher for OA than for the other diseases. OA is associated more with aging, and every year the number of sufferers of OA increases; therefore, considering costs is an important point in the prescription of medication, especially complementary medicine.
\end{abstract}

Keywords: cost of illness, fibromyalgia, osteoarthritis, rheumatoid arthritis.

\section{Introduction}

Musculoskeletal disorders are prevalent and expensive diseases. Rheumatoid arthritis (RA), osteoarthritis (OA), and fibromyalgia syndrome (FMS) are three distinct chronic disorders with different epidemiologies, etiologies, and manifestations. RA is an inflammatory autoimmune disease and is classified based on 2010 American College of Rheumatology/European League Against Rheumatism (ACR/EULAR) criteria [1]. Osteoarthritis is believed to be a disease of old age. It may not directly lead to mortality, but it does influence the quality of life largely through pain and functional limitations. Knee OA is the most common form of this disease [2]. FMS is characterized by widespread pain, tenderness, and fatigue. Its diagnosis is based on ACR clinical criteria [3].

The prevalence rates of knee and hand OA were found to be $12.4 \%$ and $8.7 \%$, respectively, $1.7 \%$ for FMS, and $0.7 \%$ for RA [4]. The prevalence rates in Iran were $15.3 \%$ and $2.9 \%$ for knee and hand OA, respectively, $0.69 \%$ for FMS, and $0.33 \%$ for RA [5]. Two or more diseases may exist simultaneously in a patient. Patients with RA may need expensive biologic treatments. In one study, the mean cost of treatment in the first year for a patient persisting with the initial treatment was $€ 12,388$ (€14,182 for adalimumab, $€ 12,103$ for etanercept, and $€ 11,002$ for infliximab) [6]. In addition to pain and disability, these diseases impose direct and indirect costs on patients and resources. Moreover, patients with these disorders may not find appropriate jobs because of their disabilities.

The economic burden of disease may be related to disease prevalence and severity, access to medical and health resources, the ability to achieve a diagnosis in a timely manner to avoid wasting funds, and physician and patient expectations [7-9]. It is necessary to evaluate costs to facilitate planning and insurance support. Previous studies have not compared the direct

* Corresponding Author: Maryam Mobini, Email: mmobini50@yahoo.com, Tel: +98 11 33350672, Fax: +98 1133264044

Received: 02 December 2016; Accepted: 25 January 2017 
and indirect costs of these three diseases. In addition, no estimation of annual costs is available for these disorders in Iran. The present study aimed to estimate the costs of each disease and compare the economic burdens they impose.

\section{Materials and Methods \\ Patients}

Three groups of participants were included in this crosssectional study. Ninety patients were in each of three groups: RA, OA, and FMS. The sample size was calculated according to Boonen et al. [10], with power and confidence levels of $90 \%$ and $95 \%$, respectively. Approval was obtained from the Ethics Committee of Mazandaran University of Medical Sciences (IR.MAZUMS.REC.95.1977).

Patients with RA fulfilled the American College of Rheumatology (ACR)/European League Against Rheumatism criteria (EULAR) [1]. OA of the knee was defined by ACR criteria [2], and FMS was characterized by widespread pain, tenderness, and fatigue and was diagnosed based on ACR clinical criteria [3]. New cases were defined as patients with symptoms lasting more than one year, but who were recently diagnosed. The participants were recruited from patients referring to private or public centers in Sari, a city in northern Iran, in the years 2015-16. All patients were evaluated by a rheumatologist, and their diagnoses were confirmed based on classification criteria. This study was conducted with the consent of patients. Patients with more than one disorder or overlapping syndromes were not included the study.

\section{Data source}

All patients completed a questionnaire on sociodemographic variables, a questionnaire on the clinical status of their disease, and a questionnaire investigating the costs of disease (visits, laboratory tests, and images) incurred by participants in the previous year.

\section{Questionnaires}

Socio-demographic questionnaire. This questionnaire investigated demographics and basic characteristics, including age, gender, educational level, marital status, and employment.

Educational level was divided into illiterate or lower than high school, high school diploma, and college education. For income estimation, patients were categorized as low, moderate, and high according to their self-reported economic status.

Questionnaire related to clinical status. According to each patient group, the second questionnaire was the health assessment questionnaire (HAQ) for RA, the Western Ontario and McMaster Universities Arthritis Index (WOMAC) for knee OA, and the Revised Fibromyalgia Impact Questionnaire (FIQR) for FMS. The Persian versions of all of these questionnaires were available and had been previously evaluated for reliability and validity in Iranian patients [11-13].

Questionnaire related to medical costs. Estimations of medical costs included direct costs and indirect costs due to disability. All consultations with health professionals, including general practitioners (GP) or specialists; the number of visits; hospital admissions; numbers and types of tests, imaging, or other related treatments (e.g., physiotherapy, acupuncture, prescribed diets for weight loss, and intraarticular injections); all drugs taken (both prescribed and over the counter), the dosage, and the frequency and duration of administration were recorded. The cost of all of these items were calculated according to government resources utilized and the portion paid by the patient. The costs of prescribed and complementary drugs were calculated by the pharmacy price. Indirect costs included absence from paid work (days per week), hours per day without functional activity due to disease, and paid and nonpaid household help.

Estimation of costs. Medical costs were recorded based on the currency of Iran (Rials), and cost estimations were made for the year 2016. Then costs were converted into US dollar figures by dividing them by 35,000 .

\section{Statistical analysis}

Statistical analyses were performed using descriptive analysis for demographic and basic characteristics of patients, one way ANOVA and chi-square tests to make comparisons of the three groups, and post-hoc ANOVA and Tukey tests for pairwise comparisons of diseases using SPSS version 20. A p-value $<0.05$ was considered significant.

\section{Results}

\section{Patients}

Two hundred and seventy patients, 90 patients with RA, 90 patients with OA, and 90 patients with FMS, were included in the current study. Demographic, socioeconomic, and clinical characteristics, cost analyses for each group, and comparisons among the groups are shown in Table 1. Duration of disease was significantly longer in RA $(\mathrm{P}<0.001)$. New cases in each group included $1(1.1 \%)$ in RA, $16(17.8 \%)$ in OA, and $43(47.8 \%)$ in FMS patients $(\mathrm{P}<0.001)$. Twenty-nine 
(10.7\%) patients referred to a government clinic, and $241(89.3 \%)$ patients referred to a private clinic.

\section{Costs}

In all groups, age was correlated with higher scores (correlation was considered significant for $\alpha$ values of 0.05 and 0.01). Educational level was higher in FMS patients, and disease duration was longer in RA patients; there were no significant correlations between total costs of disease and educational level or disease duration $(\mathrm{P}>0.05)$.

Figure 1 is the columnar chart comparing total costs of the three diseases. Table 2 demonstrates a comparison of the number of referrals for diagnostic and therapeutic management per year in RA, OA, and FMS. Table 3 shows a comparison of annual direct costs of disease in RA, OA, and FMS and the amount of disability.

\section{Impact of disease on patients and costs}

The mean HAQ score in RA patients was $0.91 \pm 0.5$, the mean WOMAC score in OA was $20.26 \pm 12$, and the mean FIQR score was $44.44 \pm 13.5$. Neither the HAQ score (in RA patients) nor the WOMAC score (in OA patients) were correlated with costs of medication or laboratory and imaging investigations; however, they both were correlated with hours in a day without functional activity and absence from paid work. In FMS, the FIQR score was directly correlated with imaging investigation costs. (Correlation was significant at levels of 0.05 or 0.01 ).

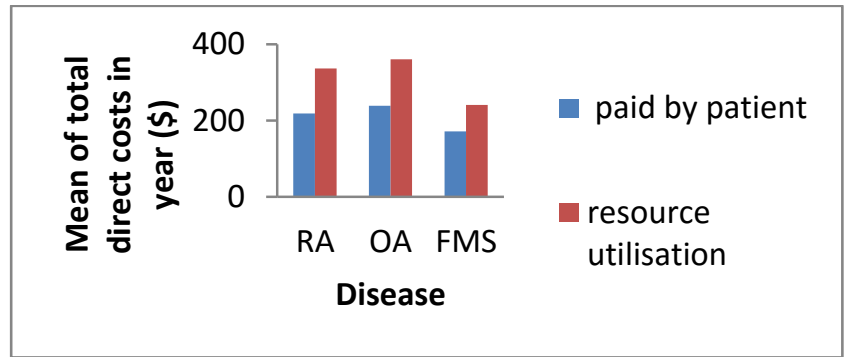

Fig. 1. Columnar chart comparing total costs of three diseases

Table 1. Demographic and socioeconomic characteristics of patients with RA, OA, and FMS

\begin{tabular}{|c|c|c|c|c|c|}
\hline & & RA group $(\mathrm{N}=90)$ & OA group $(\mathrm{N}=90)$ & FMS group $(\mathrm{N}=90)$ & P Value \\
\hline \multicolumn{2}{|l|}{ Age (year) } & $55.38 \pm 12.2$ & $58.16 \pm 11.3$ & $45.34 \pm 11.7$ & 0.000 \\
\hline \multicolumn{2}{|l|}{ Sex: Female $(\%)$} & $80(88.9 \%)$ & $80(88.9 \%)$ & $90(100 \%)$ & 0.005 \\
\hline \multicolumn{2}{|c|}{ Duration of disease diagnosis (years) } & $8.75 \pm 6.5$ & $4.94 \pm 4.3$ & $3.27 \pm 3.0$ & 0.000 \\
\hline & Illiterate & $26(28.9 \%)$ & $37(41.1 \%)$ & $11(12.2 \%)$ & \\
\hline \multirow{2}{*}{ Education level } & High school education & $38(42.2 \%)$ & $37(41.1 \%)$ & $53(58.9 \%)$ & 0.000 \\
\hline & College education & $26(28.9 \%)$ & $16(17.8 \%)$ & $26(28.9 \%)$ & \\
\hline \multicolumn{2}{|l|}{ Paid work $(\%)$} & $24(26.7 \%)$ & $16(17.8 \%)$ & $21(23.3 \%)$ & 0.000 \\
\hline & Low & $17(18.9 \%)$ & $12(13.3 \%)$ & $26(28.9 \%)$ & \\
\hline \multirow[t]{2}{*}{ Income } & Moderate & $52(57.8 \%)$ & $49(54.4 \%)$ & $48(53.3 \%)$ & 0.048 \\
\hline & High & $21(23.3 \%)$ & $29(32.2 \%)$ & $16(17.8 \%)$ & \\
\hline \multicolumn{2}{|c|}{ Marital status (got married) } & $86(95.6 \%)$ & $84(93.3 \%)$ & $83(92.2 \%)$ & 0.917 \\
\hline
\end{tabular}

Table 2. Comparison of number of referrals for diagnostic and therapeutic management per year in RA, OA, and FMS

\begin{tabular}{|c|c|c|c|c|}
\hline & $\begin{array}{c}\text { RA group } \\
(\mathrm{N}=90)\end{array}$ & $\begin{array}{c}\text { OA group } \\
(\mathrm{N}=90)\end{array}$ & $\begin{array}{c}\text { FMS group } \\
(\mathrm{N}=90)\end{array}$ & $P$ value \\
\hline The number of general practitioner visits & $0.22 \pm 1.0$ & $0.68 \pm 1.8$ & $1.01 \pm 1.9$ & $\begin{array}{c}0.007 \\
\text { RA vs FMS: } 0.005\end{array}$ \\
\hline The number of specialist and subspecialist visits & $4.97 \pm 1.2$ & $3.26 \pm 0.9$ & $3.91 \pm 1.9$ & $\begin{array}{c}0.000 \\
\text { All pair wise } \mathrm{P}<0.008 \\
0.000\end{array}$ \\
\hline The number of laboratory evaluation & $4.10 \pm 1.5$ & $1.86 \pm 0.9$ & $1.94 \pm 0.9$ & $\begin{array}{c}\text { OA vs FMS }=0.884, \\
\text { Other } P<0.001\end{array}$ \\
\hline The number of imaging evaluation & $1.83 \pm 1.3$ & $2.21 \pm 1.2$ & $1.28 \pm 1.4$ & $\begin{array}{c}0.000 \\
\text { All pairwise } \mathrm{P}<0.016\end{array}$ \\
\hline The number of physiotherapy & $0.1 \pm 0.3$ & $0.31 \pm 0.5$ & $0.06 \pm 0.2$ & $\begin{array}{c}0.000 \\
\text { RA vs FMS P=0.69 }\end{array}$ \\
\hline The number of joint injection & $0.07 \pm 0.3$ & $0.13 \pm 0.4$ & 0.00 & $\begin{array}{c}0.010 \\
\text { OA vs FMS } \mathrm{P}=0.007\end{array}$ \\
\hline
\end{tabular}


Costs in rheumatoid arthritis, osteoarthritis and fibromyalgia

Table 3. Comparison of annual direct costs of disease in RA, OA, and FMS

\begin{tabular}{|c|c|c|c|c|c|}
\hline & $\begin{array}{c}\text { RA group } \\
(\mathbf{N}=90)\end{array}$ & $\begin{array}{c}\text { OA group } \\
(\mathrm{N}=90)\end{array}$ & $\begin{array}{c}\text { FMS group } \\
(\mathrm{N}=90)\end{array}$ & $P$ value & Comment \\
\hline $\begin{array}{l}\text { Total direct costs } \\
\text { (paid by patient) }\end{array}$ & $218.32 \pm 100.7$ & $238.61 \pm 106.9$ & $171.23 \pm 10.8$ & 0.000 & $\begin{array}{l}\mathrm{OA} \text { and RA were the same } \\
(\mathrm{P}=0.637) \text {, FMS was lower than RA } \\
(\mathrm{P}=0.001) \text { and } \mathrm{OA}(\mathrm{P}=0.000) \text {. }\end{array}$ \\
\hline $\begin{array}{l}\text { Total direct costs } \\
\text { (resource utilisation) }\end{array}$ & $336.65 \pm 215.7$ & $360.54 \pm 164.4$ & $240.67 \pm 141.2$ & 0.000 & $\begin{array}{l}\mathrm{OA} \text { and } \mathrm{RA} \text { were the same } \\
(\mathrm{P}=0.402) \text {, FMS was lower than RA } \\
(\mathrm{P}=0.001) \text { and } \mathrm{OA}(\mathrm{P}=0.008) \text {. }\end{array}$ \\
\hline Physicians visits costs & $56.40 \pm 15.2$ & $36.60 \pm 11.1$ & $41.54 \pm 23.1$ & 0.000 & $\begin{array}{l}\text { RA was the highest }(\mathrm{P}=0.000) \text {, OA } \\
\text { and FMS were the same }(\mathrm{P}=0.087) \text {. }\end{array}$ \\
\hline $\begin{array}{l}\text { Lab tests costs } \\
\text { (paid by patient) }\end{array}$ & $67.66 \pm 41.2$ & $49.72 \pm 28.3$ & $53.88 \pm 25.9$ & 0.001 & $\begin{array}{l}\text { RA was higher than } \mathrm{OA}(\mathrm{P}=0.001) \\
\text { and FMS }(\mathrm{P}=0.013) \text {, OA and FMS } \\
\text { were the same }(\mathrm{P}=0.668) \text {. }\end{array}$ \\
\hline $\begin{array}{l}\text { Lab tests costs } \\
\text { (resource utilisation) }\end{array}$ & $137.83 \pm 204.4$ & $80.38 \pm 39.5$ & $86.97 \pm 37.5$ & 0.003 & $\begin{array}{l}\text { RA was higher than } \mathrm{OA}(\mathrm{P}=0.005) \\
\text { and FMS }(\mathrm{P}=0.015) \text {, OA and FMS } \\
\text { were the same }(\mathrm{P}=0.930) \text {. }\end{array}$ \\
\hline $\begin{array}{l}\text { Costs of imaging } \\
\text { (paid by patient) }\end{array}$ & $42.29 \pm 55.7$ & $45.53 \pm 41.9$ & $24.33 \pm 32.4$ & 0.003 & $\begin{array}{l}\mathrm{RA} \text { and } \mathrm{OA} \text { were the same } \\
(\mathrm{P}=0.876) \text {, and higher than FMS } \\
(\mathrm{P}<0.05) \text {. }\end{array}$ \\
\hline $\begin{array}{l}\text { Costs of imaging } \\
\text { (resource utilisation) }\end{array}$ & $62.24 \pm 45.1$ & $53.1 \pm 66.6$ & $35.74 \pm 47.75$ & 0.004 & $\begin{array}{l}\mathrm{RA} \text { and } \mathrm{OA} \text { were the same } \\
(\mathrm{P}=0.492), \mathrm{RA} \text { was higher than FMS } \\
(\mathrm{P}=0.003) \text {, but } \mathrm{OA} \text { and FMS were not } \\
\text { significantly different }(\mathrm{P}=0.08) \text {. }\end{array}$ \\
\hline $\begin{array}{l}\text { Costs of medication } \\
\text { (paid by patient) }\end{array}$ & $49.57 \pm 49.1$ & $103.04 \pm 80.1$ & $45.70 \pm 61.3$ & 0.000 & $\begin{array}{l}\text { OA was the highest }(\mathrm{P}=0.000) \text {, RA } \\
\text { and FMS were the same }(0.941) \text {. }\end{array}$ \\
\hline $\begin{array}{l}\text { Costs of medication } \\
\text { (resource utilisation) }\end{array}$ & $72.60 \pm 66.5$ & $165.54 \pm 126.6$ & $74.08 \pm 96.7$ & 0.000 & $\begin{array}{l}\text { OA was the highest }(\mathrm{P}=0.000) \text {, RA } \\
\text { and FMS were the same }(0.99) \text {. }\end{array}$ \\
\hline $\begin{array}{l}\text { Cost of physiotherapy } \\
\text { (paid by patient) }\end{array}$ & $2.53 \pm 8.5$ & $9.95 \pm 15.6$ & $1.75 \pm 7.2$ & 0.000 & $\begin{array}{l}\text { OA was higher than RA and FMS } \\
(\mathrm{P}=0.000) \text {, RA and FMS were the } \\
\text { same }(\mathrm{P}=0.886) \text {. }\end{array}$ \\
\hline $\begin{array}{l}\text { Cost of physiotherapy } \\
\text { (resource utilisation) }\end{array}$ & $5.00 \pm 16.8$ & $20.56 \pm 56.5$ & $2.78 \pm 11.5$ & 0.001 & $\begin{array}{l}\text { OA was higher than RA }(\mathrm{P}=0.008) \\
\text { and FMS }(\mathrm{P}=0.002), \mathrm{RA} \text { and FMS } \\
\text { were the same }(\mathrm{P}=0.903) \text {. }\end{array}$ \\
\hline $\begin{array}{l}\text { Cost of joint injection } \\
\text { (paid by patient) }\end{array}$ & $0.64 \pm 3.3$ & $1.61 \pm 5.3$ & 0.00 & 0.011 & $\begin{array}{l}\text { OA was higher than FMS }(\mathrm{P}=0.008) \text {, } \\
\text { RA and OA was the same }(\mathrm{P}=0.172) \text {. }\end{array}$ \\
\hline $\begin{array}{l}\text { Cost of joint injection } \\
\text { (resource utilisation) }\end{array}$ & $1.32 \pm 6.1$ & $2.87 \pm 8.0$ & 0.00 & 0.005 & $\begin{array}{l}\text { OA was higher than FMS }(\mathrm{P}=0.003) \text {, } \\
\text { RA and OA was the same }(\mathrm{P}=0.175) \text {. }\end{array}$ \\
\hline $\begin{array}{l}\text { Absence from paid } \\
\text { work (days a week) }\end{array}$ & $0.31 \pm 1.1$ & $0.07 \pm 0.5$ & 0.00 & 0.000 & $\begin{array}{l}\text { RA was higher than } \mathrm{OA}(\mathrm{P}=0.054) \\
\text { and FMS }(\mathrm{P}=0.009) \text {, but } \mathrm{OA} \text { and } \\
\text { FMS were the same }(\mathrm{P}=0.802) \text {. }\end{array}$ \\
\hline $\begin{array}{l}\text { Hours in a day } \\
\text { without functional } \\
\text { activity }\end{array}$ & $0.77 \pm 1.8$ & $0.27 \pm 1.0$ & 0.00 & 0.000 & $\begin{array}{l}\text { RA was higher than } \mathrm{OA}(\mathrm{P}=0.014) \\
\text { and FMS }(\mathrm{P}=0.000) \text {, but } \mathrm{OA} \text { and } \\
\text { FMS were the same }(\mathrm{P}=0.289)\end{array}$ \\
\hline $\begin{array}{l}\text { Non paid household } \\
\text { help }(\mathrm{N}, \%)\end{array}$ & $11(12.2 \%)$ & $4(4.4 \%)$ & 0 & 0.005 & $\begin{array}{l}\text { RA and OA were the same }(\mathrm{P}>0.05) \text {, } \\
\text { and were higher than FMS }(\mathrm{P}=0.01) \text {. }\end{array}$ \\
\hline $\begin{array}{l}\text { Paid household help } \\
(\mathrm{N}, \%)\end{array}$ & 0 & $1(1.1 \%)$ & 0 & 0.367 & \\
\hline
\end{tabular}

\section{Discussion}

The current study demonstrated that $\mathrm{OA}$ and $\mathrm{RA}$ patients had the same total costs, and their costs were higher than those of FMS patients. The number of physician visits and costs were higher in RA patients, and they referred more often to a specialist. This may be due to RA patients' more regular visits to prevent or treat disease exacerbations and to monitor the disease and the side effects of medication.

The costs of imaging and laboratory tests were higher in RA patients too, but medication and physiotherapy costs were highest in OA patients. The cause of these differences is the nature of these disorders. RA patients require anti-inflammatory and 
disease-modifying, anti-rheumatic drugs (DMARDs), and they should be examined regularly by clinic and laboratory tests for efficacy and toxicity of treatment. Additionally, it seems that the higher medication cost in $\mathrm{OA}$ is related to the indiscriminate and excessive prescribing of nutritional supplements (e.g., chondroitin sulfate, glucosamine or piasclidine, etc.). Because of the absence of a highly effective treatment for OA, many patients and some clinicians prefer physiotherapy for rehabilitation.

The costs of joint injections were similar in RA and OA patients. Joint aspiration and injections of glucocorticoid can help control inflammation and decrease pain and disability in RA and OA patients. In OA patients, injections of hyaluronic compounds were also used. RA patients were more involved in disability, had more hours per day without functional activity, and had more absence from paid work (days per week).

In addition to the nature of the diseases, other factors seem to influence the patients' disease burdens. Age, concomitant disorders (that may cause some limitation in management), patient referral system, socioeconomic status, beliefs, patient expectations, and access to resources may change the costs of treatment in different societies. In the present study, the mean annual diseaserelated total costs per patient were $\$ 336.23 \pm 215.7$ for RA, $\$ 360.02 \pm 164.3$ for knee OA, and $\$ 170.7 \pm 107.9$ for FMS. In a study in Canada, total annual disease costs for RA and OA were $\$ 9300$ and $\$ 5700$, respectively. The presence of comorbidities is associated with disease costs for RA and OA diagnoses. Indirect costs related to RA were up to five times higher than indirect costs incurred by patients with OA [14].

In OA patients, a greater level of disability was associated with higher costs. Compared with individuals with WOMAC total scores $<15$, those with scores $>$ or= 55 had 3 times greater annual costs [15].

One study compared the direct medical and nonmedical resource utilization and the inability to perform paid and unpaid work in patients with FMS, chronic low back pain, and ankylosing spondylitis; the results indicated that direct and productivity costs were higher in FMS and CLBP [10].

In the current study, total direct costs were significantly lower in FMS than in RA and OA. This result may be due to nonspecific symptoms and gradual presentation, so the patients have repeated visits and, sometimes, unnecessary workups. FIQR had a direct correlation with costs of imaging investigations. Failure to diagnose a true case of FMS has its own costs, largely due to excess visits, investigations, and prescribed drugs or physiotherapy. This fact was proven by studies in which, following a diagnosis of FMS, decreases occurred in costs compared with the predicted trend [7, 16].

In one study, the main effect of an early diagnosis of FMS was a decrease in laboratory tests and imaging, followed by reduced pharmaceuticals, referrals, and GP visits [7]. Average annual disease-related total costs per FMS patient were $7813 €$ (\$8761 USD) [10]. In another study, the total pharmacy cost for FMS cases was $\$ 3641$ - \$3557 per patient between 2006-2010 [17]. Hospital charges for FMS are substantial, and some patients suffer some procedures mainly associated with musculoskeletal, gastrointestinal, or cardiovascular systems [9].

Annual direct costs may be different in different countries. Adjusted annual direct costs per subject for FMS were found to be significantly higher in the US (\$7087) than in France $(\$ 481 ; \mathrm{P}<0.001)$ or Germany (\$2417; $\mathrm{P}<0.001)$ [8]. In the present study, direct costs were lower in Iran than in the US, Germany, or Canada, but were closer to direct costs in France. This may be due to an underestimation of the cost of some services or the inclusion of patients with moderate disease severity.

\section{Conclusion}

Total costs were similar in RA and OA. In patients with RA, the costs of physician visits and laboratory investigations were the highest; OA patients experienced greater costs of medication and physiotherapy. The number of patients with OA due to aging is increasing; considering costs is an important point in the prescription of medication, especially complementary medicine.

\section{Conflict of interest}

The authors declare no conflicts of interest.

\section{Acknowledgments}

This research was conducted as a medical student thesis by Tahereh Karimi and was supported by the Vice Chancellor of Research and Technology, Mazandaran University of Medical Sciences. 


\section{References}

1. Aletaha D, Neogi T, Silman AJ, Funovits J, Felson DT, Bingham $\mathrm{CO}$, et al. Rheumatoid arthritis classification criteria: an American College of Rheumatology/ European League Against Rheumatism collaborative initiative. Ann Rheum Dis 2010; 69(9): 1580-8. doi: 10.1002/art.27584

2. Singh AK, Kalaivani M, Krishnan A, Aggarwal PK, Gupta SK. Prevalence of Osteoarthritis of Knee Among Elderly Persons in Urban Slums Using American College of Rheumatology (ACR) Criteria. J Clin Diagn Res 2014; 8(9): JC09-11. doi: 10.7860/ JCDR/2014/7763.4868.

3. Wolfe F, Smythe HA, Yunus MB, Bennett RM, Bombardier C, Goldenberg DL, et al. The American College of Rheumatology 1990 Criteria for the Classification of Fibromyalgia. Report of the Multicenter Criteria Committee. Arthritis and Rheumatism 1990; 33(2): 160-72.

4. Branco JC, Rodrigues AM, Gouveia N, Eusebio M, Ramiro S, Machado PM, et al. Prevalence of rheumatic and musculoskeletal diseases and their impact on health-related quality of life, physical function and mental health in Portugal: results from EpiReumaPt- a national health survey. RMD Open 2016; 2(1): 2015-000166. doi: 10.1136/ rmdopen-2015-000166.

5. Davatchi F1, Jamshidi AR, Banihashemi AT, Gholami J, Forouzanfar MH, Akhlaghi M, et al. WHO-ILAR COPCORD Study (Stage 1, Urban Study) in Iran. J Rheumatol 2008 Jul; 35(7): 1384.

6. Degli Esposti L, Favalli EG, Sangiorgi D, Di Turi R, Farina G, Gambera M, Ravasio R.
Persistence, switch rates, drug consumption and costs of biological treatment of rheumatoid arthritis: an observational study in Italy. Clinicoecon Outcomes Res 2016 Dec 21; 9:9-17. doi: 10.2147/ CEOR.S108730.

7. Annemans L, Wessely S, Spaepen E, Caekelbergh K, Caubere JP, Le Lay $\mathrm{K}$, et al. Health economic consequences related to the diagnosis of fibromyalgia syndrome. Arthritis and rheumatism 2008; 58(3): 895902. doi: 10.1002/art.23265.

8. Knight T, Schaefer C, Chandran A, Zlateva G, Winkelmann A, Perrot S. Health-resource use and costs associated with fibromyalgia in France, Germany, and the United States. Clinicoecon Outcomes Res 2013; 5:171-80. doi: 10.2147/CEOR. S41111.

9. Haviland MG, Banta JE, Przekop P. Hospitalisation charges for fibromyalgia in the United States, 1999-2007. Clin Exp Rheumatol 2012; 30 (6 Suppl 74): 129-35.

10. Boonen A, van den Heuvel R, van Tubergen A, Goossens M, Severens JL, van der Heijde D, et al. Large differences in cost of illness and wellbeing between patients with fibromyalgia, chronic low back pain, or ankylosing spondylitis. Ann Rheum Dis 2005; 64(3): 396-402. doi: 10.1136/ard.2003.019711.

11. Nadrian H, Moghimi N, Nadrian E, Moradzadeh R, Bahmanpour $\mathrm{K}$, Iranpour A, et al. Validity and reliability of the Persian versions of WOMAC Osteoarthritis Index and Lequesne Algofunctional Index. Clin Rheumatol 2012; 31(7): 1097-102. doi: 10.1007/ s10067-012-1983-7.

12. Rastmanesh $\mathrm{R}$, Rabiee $\mathrm{S}$, Shaabani $Y$, Mazinani $H$,
Ebrahimi AA, Jamshidi AR. Validation of the Persian version of the Stanford Health Assessment Questionnaire (HAQ) in patients with rheumatoid arthritis. $J$ of Paramedical Sciences (JPS) 2010; 1(1): 16-25.

13. Mobini M, Mohammadpour R, Elyasi F, Hosseinian A Abbaspour S. Validity and Reliability of the Persian Version of Revised Fibromyalgia Impact Questionnaire in Iranian Patients with Fibromyalgia. $J$ Mazandaran Univ Med Sci 2016; 25(133): 119-27.

14. Maetzel A, Li LC, Pencharz J, Tomlinson G, Bombardier C. The economic burden associated with osteoarthritis, rheumatoid arthritis, and hypertension: a comparative study. Ann Rheum Dis 2004; 63(4): 395-401. doi: 10.1136/ard.2003.006031.

15. Gupta S, Hawker GA, Laporte A, Croxford R, Coyte PC. The economic burden of disabling hip and knee osteoarthritis (OA) from the perspective of individuals living with this condition. Rheumatology 2005; 44(12):1531-7. doi: 10.1093/ rheumatology/kei049.

16. Kim SK, Kim SH, Lee CK, Lee HS, Lee SH, Park YB, et al. Effect of fibromyalgia syndrome on the health-related quality of life and economic burden in Korea. Rheumatology 2013; 52(2): 311-20. doi: 10.1093/ rheumatology/kes 255 .

17. Jeffery DD, Bulathsinhala L, Kroc M, Dorris J. Prevalence, health care utilisation, and costs of fibromyalgia, irritable bowel, and chronic fatigue syndromes in the military health system, 20062010. Mil Med 2014; 179(9): 1021-9. doi: 10.7205/MILMEDD-13-00419. 